\title{
Looping the evolutionary loop
}

The Origins of Life: From the Birth of Life to the Origin of Language

by John Maynard Smith and

Eörs Szathmary

Oxford University Press: 1999. 180 pp. $£ 18.99$

\section{Gabby Dover}

One of the sadistic pleasures to be had from the defunct age of selfish-genery was to witness the mental loops of its proponents as they tried to extricate themselves from the illogical cul-de-sacs of their own devising. In his writings, Richard Dawkins' pseudo"paradox of the organism" was the climactic apotheosis of a belief in his own rhetorical devices which forced him to suspend all scientific rationale and modesty.

The argument is as follows and, in the interests of fairness, I quote directly: "the organism should, by rights, be torn apart by its competing replicators", yet "the organism functions as such a convincingly unified whole that biologists in general have not seen there is a paradox at all!". The genes get around this little problem by deciding on a minimum shared list of "desiderata" of what to do: “They all 'agree' over what is the optimum state of every aspect of phenotype, all agree on the correct wing length, leg colour ... etc.". This Dawkinsesque loop now begs the question: which is the unit of selection? Is it the selfish gene or the organism (the collective love-in of happy, hippy desiderata lists)?

For 'biologists in general', there has to be some way out of this impasse if genes are to be rescued from the charge of being unreconstructed hooligans flashing their absurd desiderata lists. Have John Maynard Smith and Eörs Szathmary come to the rescue? After reading The Origins of Life, I can't make up my mind. There is an ambivalence in their evolutionary models of the origins of cooperativity that confounds the issue. What is clear is that their starting assumption is pure selfish-genery: "We have to explain how complex entities evolved, despite selection between their components favouring selfish behaviour." Accordingly, this assumption becomes Life's Critical Problem Looking for a Solution, with regards not only to the paradox of the organism, but also to a range of other "major transitions" during evolution. Houston, we have a problem.

There is no point in arguing over the transitions as life on Earth became more 'complex': lonely replicators begat groupie replicators in cells; free-floating replicators begat chromosomes; RNA genes and RNA enzymes begat DNA and proteins; prokaryotes begat eukaryotes; asex begat sex; single cells begat multicells; solitary individuals begat colonies and primate societies begat human, speaking societies. The interesting arguments concern (i) whether lower-level desires would rip apart higher-level cooperation and (ii) whether there is one overarching principle that gets life through these problematical bottlenecks.

In order to lay out their stall regarding argument (i), Maynard Smith and Szathmary first need to dismiss 'group selection' which has, over the past two decades, become the bête noir of selfish-genists. Group selection does not work, "for individual selection will win out in most cases". However, a recent masterly review of the theory and practice of group selection, Unto Others: The Evolution and Psychology of Unselfish Behavior (Harvard University Press) by Elliott Sober and David S. Wilson, shows that it works in ecologically patchy circumstances most likely to be the natural state of affairs for most life-forms. Furthermore, there is an ultimate irony in what Maynard Smith and Szathmary call their "stochastic corrector model" required under argument (ii), in that it is seemingly rooted in group selection. Indeed, their figure legend of the model ends on the solid note, "group selection can win out", contrary to other statements in the text that "there is no need to invoke group selection" for the transitions.
The stochastic corrector model works as follows: two selfish, free-floating replicators (one type better than the other) find themselves in the first protocells. They begin to replicate, as do the cells, and distribute themselves willy-nilly to new daughter cells. Now comes the trick: insist that only cells inheriting equal numbers of the two replicator types inherit the Earth. Then, plug this little trick into a compliant computer program to see whether what goes in also comes out. The result - "the survival of cooperators" in the establishment of the first cells by group selection.

Group selection versus individual selection (especially when the latter is dumbeddown to genic selection) is not some arcane squabble; it goes to the heart of the phenomenon we call biology, in which thousands of molecules cooperate in bringing to life the all-singing, all-dancing, reproducing organism, passing on the DNA baton from one generation to the next. The ultimate explanation, in my view, will have no more to do with supposedly autonomous selfish replicators than with the vague inner mysteries of holistic biology.

Biology evolved from simple beginnings. We can rid ourselves of the supposedly 'independent' meddlesome replicators if we face up to the reality that there has been, in all

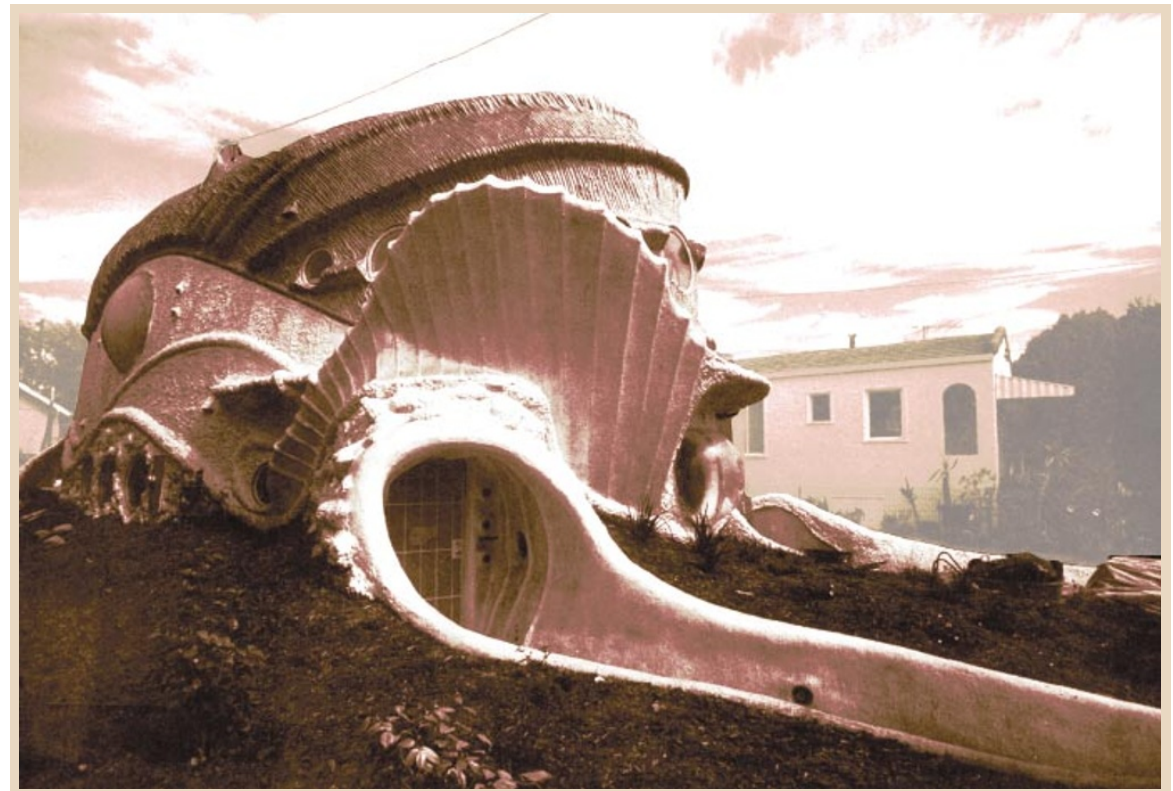

\section{Home is what comes naturally}

This is not a fossilized art nouveau dinosaur, but a piece of so-called evolutionary architecture. The house shown above, created by Eugene Tsui for his parents, is built with materials and with a structure that will withstand earthquakes, flooding, windswept fires and vermin, while a south-facing 'eyeball window' acts as a heat- and light-magnifying device. But only time will tell whether it is truly adapted to its environment. In his book Evolutionary Architecture: Nature as a Basis for Design (Wiley, \$54.95), Tsui suggests that the natural world, for instance a termites' nest or dinosaur bone, can become models for architectural problem-solving. 
probability, an intimate, functional 'crosstalk' between consenting molecules of RNA (DNA) and proteins from the Big Origin. Such molecules were small in number, and remain relatively small in number 4.5 billion years later, given the recent findings of rather few (around 2,000) modules (at the DNA and protein levels) shared by approximately 100,000 mosaic genes and proteins. Life is about molecular coevolution between redundant, modular parts, subject to frequent genomic turnover, which have been more than happy to cooperate, in a bewildering variety of combinatorial permutations. Our genes are born to cooperate; they are not full of angry resentment over a 'forced' cohabitation that has been occurring since time immemorial.

If we ditch the selfish-replicator illusion, and accept that the only known biological entity capable of autonomous replication is the cell (full of cooperating genes and proteins, etc.), then we can begin to tackle other events, for example the 'paradox' of the DNA-protein transition stage raised by Maynard Smith and Szathmary. DNA replication is so error-prone that it needs the prior existence of protein enzymes to improve the copying fidelity of a gene-size piece of DNA. "Catch-22," say Maynard Smith and Szathmary. So, wheel on RNA with its now recognized properties of carrying both informational and enzymatic activity, leading the authors to state: "In essence, the first RNA molecules did not need a protein polymerase to replicate them; they replicated themselves." Is this a fact or a hope? I would have thought it relevant to point out for 'biologists in general' that not one self-replicating RNA has emerged to date from quadrillions $\left(10^{24}\right)$ of artificially synthesized, random RNA sequences.

So, the "problem" remains; but did it ever exist? Fair play among
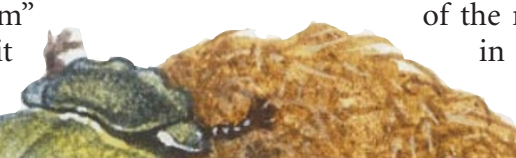

dung and corpses.) While much schoolboy humour is strongly faecal (are schoolgirls equally fascinated?), death remains "the one we don't mention".

Defaecation is an inevitable and unavoidable consequence of animal feeding, whether animals possess a true gut or not. And the endproduct can tell us a great deal about where the animal has been living, what it has been feeding on, the quality of its food Faecophilia: a dung beetle's life begins in dung and is sustained by it. and, in some cases, how much it has eaten. The hairs of a mammal, the feathers of a bird, or plant cuticles, all found in faeces, have been used for many years as indicators of feeding habits. Even the fossilized remains of ancient turds known as coprolites may be used to predict diet. Such studies are of considerable interest to forensic scientists, either in relation to dung or to carrion, because the plants, animals and substrates associated with different habitats leave traces that may be powerful indicators of the site of death or deposition.

Humans tend to defaecate in private, probably because crouching during elimination would make them vulnerable to predators or enemies, or transmit disease. But many other mammal species have incorporated this unavoidable activity into their behavioural repertoire. In this case, even squatting during defaecation (or urination) has become ritualized as part of their territorial behavioural signals. Add to this the size, shape, colour and odour of the dung, and we have a powerful source of information on the animals living in a locale. In many cases, of course, animals such as rhinos and hippos may scatter their dung during or after defaecation to enhance its territorial value. Alternatively, dung might be intentionally accumulated in middens to enhance the value of a signal, the site frequently being used by a number of species.

The vigorous activity of dung beetles has impressed people since the time of the Ancient Egyptians, who immortalized the industry of the scarab beetles in their art and religion. In more recent times, Fabre studied the behaviour and biology of a range of dung-beetle genera and species in southern France, demonstrating the numerous niches for different dung types depending on the size and texture of individual droppings. Most of these beetle species, once they have emerged from their pupae, roll or gather dung to feed on until they are sexually mature. They then lay their eggs in dung balls, or 'sausages', that they have buried in their nest chambers. The activity of these insects plays a significant ecological role in environments dominated by large mammals, where their dung-burying activities enhance fertilization, aeration and the percolation of rain into the soil.

Ralph Lewin is clearly a dedicated and entertaining faecophile. It is refreshing to find a scientist who takes neither his subject nor himself too seriously, observing, no doubt to the chagrin of many colleagues, that "It seems a shame that the good name of bullshit, a potentially useful product, should have been debased in recent parlance to signify worthless or misleading statements". Contentiously, the author tells us that the words 'science' and 'shit' are both derived from the same ancient Indo-European root.

The removal of accumulated human waste cannot be ignored in these faecal equa- 